\title{
Service System Decoupling for Mass Customization: A Case Study in Catering Services
}

\author{
Jue CHEN ${ }^{1}$, Yunhong HAO ${ }^{2}$ \\ ${ }^{1}$ The tourism school, Zhejiang Gongshang University, Hangzhou, China; ${ }^{2}$ School of Business Administration, Zhejiang Gongshang \\ University, Hangzhou, China. \\ Email: chenjue8@yahoo.com
}

Received April 17, 2009; revised June 19, 2009; accepted July 28, 2009.

\begin{abstract}
The paper examines the key issues on system decoupling in service operations of mass customization by conducting a case study in catering services. It firstly justifies the effectiveness of applying concept of mass customization into service system decoupling to deal with the operation dilemma and then reveals the nature of decoupling decisions for mass customization purpose after discussions on the importance of modularization and the role of technologies including IT in the decoupling process. Based on these analyses, a Judgment-Matrix-based model on how to make the decoupling decisions in balancing the multiple operation objectives is then proposed and further research directions are finally suggested.
\end{abstract}

Keywords: Mass Customization, System Decoupling, Customer Contact, Modularization

\section{Introduction}

System decoupling is an effective approach to cope with the influences caused by customer contact by dividing the service system into two components: back-stage and front-stage. However the relevant researches often take a dichotomous perspective, assuming that the objectives of service operations focus on either efficiency (costs and related issues) or services (customization and responsiveness). Mass customization (MC) has been regarded as an innovative way of doing business by putting together these seemly contradictory operation objectives and hence one of the most advanced operation model in $21 \mathrm{st}$ century. The paper intends to discuss the system decoupling issue in the context of service mass customization which requires a comprehensive consideration of the various operation objectives rather than dichotomous thinking. This in addition will also lead to an extended application of manufactory-originated MC theory into the service sector.

The remainder of this paper is structured as follows. To begin with, we review current literatures addressing both service system decoupling and MC, which leads to the suggestion of research questions. Then the propositions of basic consideration on system decoupling for mass customization and a relevant model for decoupling decision-making are presented. Next, we conduct a case study in a restaurant, based on which implications are drawn for justification of the previous propositions. Finally, the paper ends with conclusions and suggestions for further research.

\section{Literature Review and Research Questions}

\subsection{Customer Contact and Service System Design}

One of the most distinct features for services (services in this paper refer to general "business services" in "real world" rather than the services in virtual world such as web or software services) is customer contact, which means that customer should be physically present in the service delivery system [1]. The customer contact provides a source of complexity that is not generally found in manufacturing operations [2]. Contacts with the customers and their involvement in the service delivery process affect the effectiveness and efficiency of services operations. Customer contact is a double-edge sword to the service system, bringing up both risks and opportunities. It on one hand introduces uncertainties and variation in the service delivery system and makes demands on the design of facilities, staff and technology in the production system [3]. On the other hand, customer contact provides valuable opportunities for responding to a customer's needs and cross-selling other products [4] and involving customer self-services which would help increasing efficiency for the organization [5]. 


\subsection{Service System Decoupling}

\subsubsection{Decoupling for Efficiency}

To deal with the influences caused by customer contact some researchers introduced decoupling approach breaking the service system into its component back and front-office stages. According to the customer contact approach proposed by Chase and Tansik [1,6,7], customer contact activities should be decoupled from non-contact activities to do justice to their different design requirements and maximize the efficiency of the service delivery system. Consequently, service organizations consist of a front stage and a back stage. In the back office customer contact is passive or nonexistent, service processes may be designed with manufacturing-like principles in mind [6]. The process may take advantage of standardization and automation to enhance the efficiency and effectiveness of operations. While in the front stage customer contact is high and active, it brings about unavoidable inefficiencies, and the human relation skills become a dominant factor in designing the process [6]. Study [8] adds that moving some of the back-stage functions from developed areas (or even countries) to underdeveloped regions may increase greatly efficiency because of the reduction in labor costs and taxation.

\subsubsection{Decoupling for Speed, Quality and Sales Opportunities}

However, back-stage tasks need not only be viewed as tasks where efficiency is the sole purpose. Research [9] and [10] propose using the back office to provide superior results in non-cost strategies by linking the back office to the same marketing directives that the front office is organized around. This represents a change in focus from managing for cost containment and transaction management to managing for revenue enhancement and customer loyalty by aligning the back office for speed or high quality (eg. flexibility, customization and similar features of services).

Chase and Hayes realize the limitation of previous study that they overlooked the fact that there are positive benefits to both the customer and the organization by having the customer contact [4]. Afterwards Chase and
Aquilano propose a matrix for discovering the tradeoff between sales opportunities and efficiency in service system design. More back stage decoupled from the front stage means more system efficiency but less sales opportunities [11].

Metters and Vargas hold that in several situations coupling front office and back office jobs can be a viable strategy and both coupled and decoupled system designs can support efficiency and high-quality service strategies [12].

\subsubsection{Summery on the Decoupling Approach}

Based on the literature reviewed above we could summarize the tradeoffs (or dilemma) involved between contact benefits of the front-stage operations and the potential efficiency of the limited or no contact back-stage operations. In another word, the low decoupling (focusing on front-stage) or high decoupling (focusing on back-stage) in service system brings different advantages for service operations as summarized in Table 1. The decoupling approach should reduce costs and increase productivity, but these advantages may be off-set by losses in the key competitive strategies of sales opportunities and service quality (delivery speed, flexibility and customization). The method of system decoupling is in essence trying to alleviate this operational dilemma but can not provide a complete solution.

\subsection{Mass Customization and Enablers}

MC refers to the ability of production of customized goods and services on a mass basis and has recently aroused more and more academic concern. The visionary concept of MC was first coined by Stan Davis [13] in Future Perfect. And the concept of MC was first fully expound by Pine [14] who implied a view of $\mathrm{MC}$ as in some sense a historically inevitable successor to mass production, the principal in which to complete in the future. The MC is essentially an oxymoron since it puts together seemingly contradictory notions --- the production and the distribution of customized goods and services on a mass basis. In anther word, the requirements of

Table 1. Advantages form focusing on front-stage and back-stage

Advantages form focusing on front-stage (lowly decoupled system)
Advantages from focusing on back-stage

(Highly decoupled system)
1. Improving service delivery (including flexibility, customization, speed and responsiveness)

2. Increasing sale opportunities (cross selling)

3. Improving efficiency by involving customer participations
1. Improving efficiency by adopting industrial principles

2. Reducing costs on labor and taxation by favorably locating the back-stage

3. Developing expertise for the staff and thus improving service quality and speed 
MC reside with three aspects: quick responsiveness, customization and economy of scale (mass efficiency) [15]. To meet these operational objectives simultaneously, three major technical challenges in mass customization system are identified, namely maximizing reusability, fast production responding to customers' needs and integrated product life-cycle [15].

To cope with the operation dilemma and overcome the challenges in achieving MC, the following enablers have been mentioned in literature: modular design in product and process [16]; postponement and supply chain management [17]; efficient information system [18]. Among them the modularization is regarded as the most fundamental approach to reach the goal of MC. Both [14] and [16] held that modular design in product and process could facilitate MC since it helped to achieve both scale and scope economy required by $\mathrm{MC}$.

\subsection{Research Questions}

As discussed above the system decoupling has become a vital decision in service system design and an important approach (strategy) to cope with both the benefits and risks caused by customer contact in service delivery. However researches in this domain often take a dichotomous perspective, assuming that service organizations focus on either efficiency or cross-selling, either low costs or high-quality services [19]. This could not meet the requirements of $\mathrm{MC}$ in which companies perform well at multiple operation criteria (eg, cost efficiency and good services) simultaneously and provide complete solutions to operation dilemma. Then the questions could be raised if we apply the concept of MC into the service system decoupling:

- Is it effective to apply MC concept into service system decoupling?

- What is the nature of system decoupling if the concept of MC is integrated in?

- How to strike a balance in between the multiple operation objectives required by $\mathrm{MC}$ when making a decoupling decision for service system?

\section{System Decoupling for Service Mass Customization: Conceptual Propositions}

\subsection{The Nature of System Decoupling for Mass Customization}

System decoupling serves as an important decision in service system design to cope with both the benefits and uncertainties caused by customer contact and an approach to alleviate to some extent the contradiction between efficiency and service provision (including customization). However it could not provide the complete solution to this operation dilemma. The concept of MC provides a key to solve the problem. Most of the literatures as mentioned previously agreed that modularization would be the fundamental solution to MC. Therefore system decoupling for MC purpose should involve modularization in service system and make decoupling decisions based on it. Modularization is the use of modules to facilitate assembly and configuration of finished products [20]. It can be used to develop complex products or services using similar component which may lead to high efficiency. Therefore in the condition of modularization the service system decoupling issue is in nature to determine the allocation of service modules to back or front stage rather than a geographical or physical separation of the system.

\subsection{Decoupling Decisions in Service Mass Customization}

As mentioned above the service functions to be provided in service MC system should be rationalized into service modules. Thus the decoupling decisions in service MC system can be converted into the front or back stage decisions for each service module. Here we propose a two-step method for these decisions.

Firstly the decoupling decisions should be made for each service module according to the extent of customer contact since the latter is the decisive factor for the decisions as discussed previously. The decoupling decisions for high contact service modules (modules can not be provided without customer contact) are quite simple since they "have to" be arranged in front-stage while the middle and low contact service modules (modules can be provided without customer contact) can be located either in front or back office. The decoupling decisions therefore in essence should only be made for these modules with middle and low customer contact.

Secondly there are also exceptions in high contact modules whose degree of customer contact could be changed by introducing technologies since the nature of customer contact is changing nowadays [21] due to the developments in technology including IT. Those modules together with the middle and low contact modules are here named as "free modules", meaning that they are "non-high-contact" and hence can be allocated to either front office or back office. The "free modules" are left for a further comprehensive decoupling decision-making as discussed in the following section.

\subsection{The Model of Comprehensive Decoupling Decision for "Free Modules"}

\subsubsection{The Model and Explanation}

Here we propose a basic model demonstrating the comprehensive consideration for decoupling decisions of the "free modules" and method to conduct these decisions. The model is based on the understanding that decoupling decisions need comparative evaluation of the benefits obtained from allocating service module to front-stage and back-stage respectively, which are summarized in Table 1. The model is shown as Formula 1 below. 


$$
\mathrm{S}=\frac{\sum_{\mathrm{i}=1}^{3} \mathrm{~F}_{\mathrm{i}} \gamma_{F_{i}}}{\sum_{\mathrm{j}=1}^{3} \mathrm{~B}_{\mathrm{j}} \gamma_{B_{j}}}
$$

and $\sum_{i=1}^{3} \gamma_{F i}=100 \%, \sum_{j=1}^{3} \gamma_{B j}=100 \%$

In Formula $1, \mathrm{~S}$ refers to the final result of the decoupling decision for a "free module". If it is greater than 1 , the service module should be allocated to the front stage and to the back stage if it is less than 1 .

$\mathrm{F}_{\mathrm{i}} \gamma_{\mathrm{Fi}}$ denotes the total benefit (or grade) that can obtain from allocating the module to front stage; $F_{i}$ denotes the benefit (or grade) in each specific aspect that can obtain from allocating the module to front stage, as demonstrated in Table 2 which is based on the analysis in Table 1. $F_{1}$, for example, means the benefit that can get from improving service delivery by putting the module in front-stage. $\gamma_{F i}$ denotes the weights associated with the benefit in each specific aspect.

Similarly, $\mathrm{B}_{\mathrm{j}} \gamma_{B j}$ denotes the total benefit (or grade) that can obtain from allocating the module in back stage; $\mathrm{B}_{\mathrm{j}}$ denotes the benefit (or grade) in each specific aspect that can obtain from putting the module in front stage, also explained in Table 2. $\gamma_{B j}$ denotes the weights associated with the benefit in each specific aspect.

Managers and experts' evaluation may help to get the values of $F_{i}$ and $B_{j}$. The values can be estimation of the direct economic benefits, or subjective grading based on their experiences and knowledge. Therefore the key of the decoupling decision-making in Formula 1 is the assessment of weight values associated with the benefit in each specific aspect, namely the value of $\gamma_{B \mathrm{i}}$ and $\gamma_{F \mathrm{i}}$. We can obtain them by calculating the relative importance with Judgment Matrix as described in the following sections.

\subsubsection{The Judgment Matrix}

We build two Judgment Matrixes respectively by using two groups of judgment objects with three each. These judgment objects come from the benefit in each specific aspect that can obtain from allocating the module to front or back stage, namely the $\mathrm{F}_{1}, \mathrm{~F}_{2}, \mathrm{~F}_{3}$ and $\mathrm{B}_{1}, \mathrm{~B}_{2}, \mathrm{~B}_{3}$ as explained in Table 2.

In the judgment matrix $F=\left[f_{i j}\right], f_{i j}$ denotes the relative importance for $F_{i}$ versus $F_{j}$, and $i, j=1,2,3$. Similarly in judgment matrix $B=\left[b_{i j}\right], b_{i j}$ denotes the relative importance of $B_{i}$ over $B_{j}$, and $i, j=1,2,3$. The judgment matrix is symmetrical and consistent, that is: $\mathrm{f}_{\mathrm{ik}} \cdot \mathrm{f}_{\mathrm{kj}}=\mathrm{f}_{\mathrm{ij}}$.

It is therefore obvious that the greater the value is, the more important the factor $i$ is. A judgment scale with five properties can be applied: 1 to 5 respectively denotes that factor $\mathrm{i}$ and $\mathrm{j}$ are the same important, more important, important, very important and extremely important. We also need to do single-sort of hierarchy in the factor values and consistency test.

\subsubsection{Consistency Test}

The indicators for consistency test is

$$
\text { C.I. }=\frac{\lambda_{\text {max }}-\mathrm{n}}{\mathrm{n}-1},
$$

and $\lambda_{\max } \approx \frac{1}{\mathrm{n}} \sum_{\mathrm{i}=1}^{\mathrm{n}} \frac{(\mathrm{F} \gamma)_{\mathrm{i}}}{\gamma_{\mathrm{i}}}=\frac{1}{\mathrm{n}} \sum_{\mathrm{i}=1}^{\mathrm{n}} \frac{\sum_{\mathrm{j}=1}^{\mathrm{n}} \mathrm{f}_{\mathrm{ij}} \gamma_{\mathrm{j}}}{\gamma_{\mathrm{i}}}$,

and $(\mathrm{F} \gamma)_{\mathrm{i}}$ denotes the $\mathrm{i}_{t h}$ factor of vector $\overrightarrow{\mathrm{F} \gamma}$.

Then we sort for the corresponding indicator named R.I., and calculate the ratio of consistency:

$$
\text { C.R. }=\frac{\text { C.I. }}{\text { R.I. }}<0.1,
$$

by which to determine whether it is consistent.

\subsubsection{Calculation on the Weights of Factors}

We calculate it by means of the Root Square Method, formulas are as follow:

Table 2. Indications of $F_{i}$ and $B_{j}$

$\mathrm{F}_{\mathrm{i}}$ (Benefits for modules being allocated in front-stage)

$\mathrm{F}_{1}$ Improving service delivery (including flexibility, customization, speed and responsiveness)

$\mathrm{F}_{2} \quad$ Increasing sale opportunities (cross selling)

$\mathrm{F}_{3} \quad \begin{aligned} & \text { Improving efficiency by involving customer participa- } \\ & \text { tions }\end{aligned}$
$\mathrm{B}_{\mathrm{j}}$ (Benefits for modules being allocated in back-stage)

$\mathrm{B}_{1} \quad$ Improving efficiency by adopting industrial (rationale) principles

$\mathrm{B}_{2} \quad$ Reducing costs on labor and taxation by favorably locating the back-stage

Beveloping expertise for the staff by decoupling and thus improve service quality and speed 


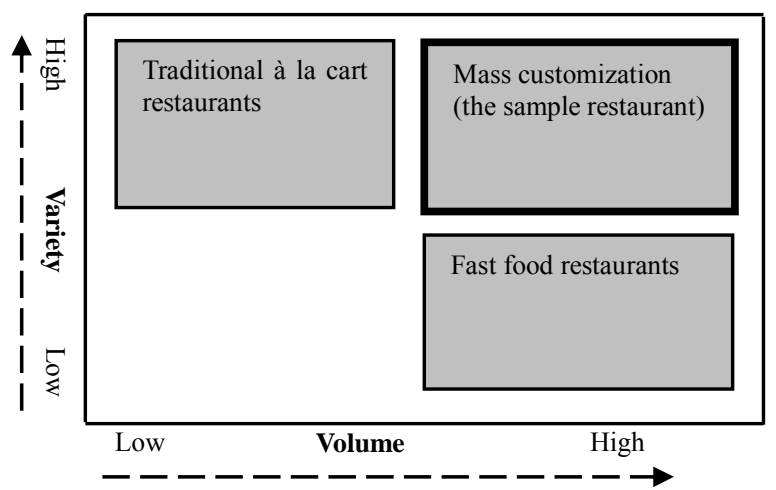

Figure 1. Volume-variety matrix for process type

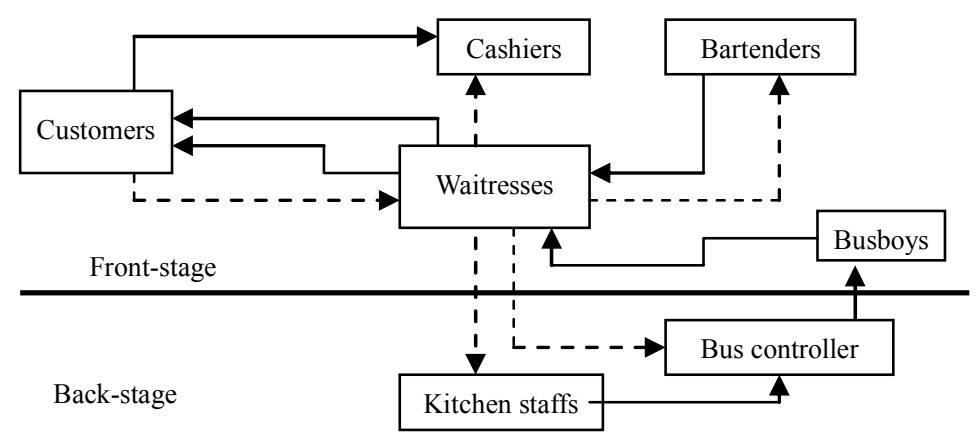

Figure 2. The service process mapping

Weight is: $(\gamma)_{i}=\left(\prod_{j=1}^{n} f_{i j}\right)^{\frac{1}{n}}$

Relative weight is: $(\gamma)_{\mathrm{i}}^{0}=\frac{\gamma_{\mathrm{i}}}{\sum_{\mathrm{i}} \gamma_{\mathrm{i}}}$

The relative weight $(\gamma)_{i}^{0}$ is just the percentage of weighted average, namely the $\gamma_{\mathrm{Fi}}$ or $\gamma_{\mathrm{Bi}}$ we want to obtain. Then with the values of $F_{i}$ and $B_{j}$ we can calculate the final value of $\mathrm{S}$ in Formula 1, thus completing the decision-making of front or back stage for the module.

\section{The Case and the Problem Analysis}

\subsection{The Sample Organization and Problems}

The research sample was a private à la càrt restaurant located in eastern China. It had 800 dinning capacity and could provide around 300 dish items according to its menu. However the restaurants had been suffering revenue decline since the enlargement of its operation scale and received plenty of complaints showing customers' dissatisfactions. As the members of Consultancy Services we were invited to diagnose the problems and propose possible improvement measures. Based on a statistic analysis we found that the major problems should be put priority on the low speed and inefficiency and inadequacy of service delivery such as too long and unfair waiting time, service staffs "absence" from customers, slow response to customer's additional order or special requirements, etc. In addition, the complaints come mostly from the "walk in" customers who had experienced the à la cart services.

\subsection{Identification of Process Type and Service Process Mapping}

We began with the identification of the operation type of the restaurant based on volume-variety analysis, giving us a general understanding of the nature of the business. There existed obvious differences in between the sample restaurant and traditional à la càrt restaurants and fast food restaurants. The traditional à la càrt restaurant provided wide rang of customized food and services but in very small volume while the fast food restaurant produced a large volume of dishes within very limited variety. Whereas the sample restaurant could provide wide variety of food and services on a relatively mass basis, it therefore should be positioned in the mass customization area in the volume-variety matrix as shown in Figure 1.

The à la cart service process of the restaurant with a clear decoupling of the front-stage and back-stage could be described in Figure 2. The à la cart services were provided through a paper-based information flow. There 
were two sorts of order sheets for waitresses to keep down customers' orders. One was the order sheet for dishes, the other was for drinks. After having taken customers' orders, the waitresses would send 3 copies of the order sheets for dishes respectively to kitchen staffs and bus controller and cashiers, and send 2 copies of the sheet for drinks to bartenders and cashiers. Receiving the order sheet for dishes, the kitchen staff would cook to orders and then send the cooked dishes to the bus controllers. The latter would check the dishes with the order sheets and then tell busboys to carry them to the corresponding tables with helps from the waitresses. For the drinks services, the bartenders would prepare drinks according to the order sheets and the waitresses would then fetch and take the drinks to the corresponding customers. After meal the customers would go to the check-out counter and pay the bill through the cashiers' services. In Figure 1 , the dotted line arrows refer to information flows, the line arrows refer to materials flows and monetary flows.

\subsection{Identification of the Fail Points in the Service System}

4.3.1 The Information Flows and the Service Delivery The information system in the restaurant remained as the same as they had been when the operation scale had been very small. It was a paper-based system and unable to deal with the greatly enlarged business. Firstly the waitresses had to spend 3-5minutes to deliver 3 copies of dish order sheets and 2 drinks order sheets to 4 partners: kitchen staffs, bus controller, bartenders and cashiers. This meant that the dish-cooking process and drinks preparation had to be postponed at least 3-5minutes, which seemed not a short period of time to a waiting customer. Secondly, the paper-based information system affected negatively the dish production in back-stage --the kitchen. The kitchen staffs should determine the priority of cooking as doing "scheduling" in the manufacturing. Otherwise unscheduled production would lead to not only low efficiency but also unfairness to customers. However the kitchen staffs who were in charge of the final scheduling always got "lost" in work because the paper-based information was not reliable and clear enough for them to arrange the scheduling when dealing with so many orders. Thirdly the cashiers had to collect a lot of copies of the order sheets for each table (customer) and be prone to make mistakes if too many customers check out at the same time (unfortunately it is common in catering services). We could also find similar problem among bartenders and bus controllers.

\subsubsection{The Fail Points Related to System Decoupling}

Many decoupling-related fail points could be also found in both the front-stage and back-stage. Full service catering meant longer dinning time and hence many customers would always require re-processing (such as re-heating, re-shaping and re-flavoring) some already served dishes. These requirements would be settled by sending the dishes to the kitchen and "inserting" into the routine schedule for dish production. But they had been always delayed if the kitchen had been busy and the schedule had been too tight. There had been considerably some re-processing claims from the customers. Pooling these orders together and processing them in the back-stagekitchen seemed very efficient. However this had led to delayed services and greatly reduced the responsiveness, causing customers' dissatisfaction.

Another fail point could be found in the cashier services which had been designed as front-stage activities. Cashiers had been arranged sitting behind the counter near to the exit of the dinning hall and providing check-out services in the face of customers who approached the counter after meal. The cashier had to collect all the order sheets for the customer and figured out the sum of payment immediately while they had been in many cases disrupted by the customers' further inquiry even some irrelevant questions such as "how about the weather tomorrow?" In the peak time customers had to in many cases queue before the cashier counter and mistakes in payment frequently occurred.

Drinks preparation and delivery had been inefficiently arranged, assuming the services as front office activities. According the service procedure the waitresses would pass the order sheets for drinks to the bartender who would prepare the drinks to orders one after another (it was very time-consuming). Then the waitresses would carry the prepared drinks to the corresponding table and serve to customers. This procedure would lead to the waitresses "absence from the customers" for 5-8 minutes and most of customers had been unhappy about this period of time "without services".

Cooking to fresh is the requirement for seafood and hence the seafood should be kept alive before they are ordered by customers. Most of the customers preferred ordering the seafood after seeing them alive. The waitresses would always lead the customers into the seafood-keeping area for ordering. However the area had been located as a back-stage unit far into the kitchen and hence the customers' ordering activities had inevitably caused some disturbances to the dish production in the kitchen.

\section{System Improvement and Results}

\subsection{Rationalization of the Service Functions}

Under the agreement from the top managements in the restaurant we started the re-engineering plan with the rationalization of all the service functions (or units) in the service system. After a comprehensive analysis of all the service functions and customer demands and interrelationship in between them, some of the service units were 
split and some were merged to deal with the problems mentioned above. The drinks-carrying services originally conducted by waitresses, for example, were taken away and merged with function of drinks-preparation to form a new service unit-“drinks service centre", which aimed to increase greatly the efficiency in drinks service. Another example was the split of the original reservation unit into two: the "reservation" and the "Planning and decoration" for enhancement of the growing banqueting services. Similarly many service functions were rationalized based on the utilization of commonality within service units and facilitation of service provision. More shared units were identified after the rationalization and hence the service functions in the restaurant decreased from 33 to 25 .

\subsection{Re-Engineering of the Information System}

After a deep consideration the restaurants decided finally to purchase and set up a computer-based dish-order system and re-design the information flow for the service process. In the new information flow the waitresses would just input the customers' orders into their wireless PDA and press the "confirm" button, the order information would then be automatically sent into the terminals in kitchen, bus controller, bartenders and cashiers. The back-stage production thus was triggered within seconds and saved at least 3-5minutes for the order-receiving process. Furthermore with the accurate and easy-processing information the relevant staffs (including kitchen staffs, bartenders, bus controllers and cashiers) could readily arrange their job efficiently (eg. the computer could automatically provide schedule for the kitchen staffs to organize efficient dish production).

\subsection{Re-Decoupling the Service System}

\subsubsection{Switching from Back-Stage to Front-Stage}

As mentioned early re-processing the already served dishes was arranged in the back-stage for high efficiency but incurred customers' complaints due to the slow responsiveness. The restaurant was persuaded to move this function to front-stage. Some re-heating equipments (e.g. microwave oven) and cutting appliances (e.g. knives) were purchased and placed in the dinning hall, and attractive instruction brochures of simple cooking methods in microwave oven and some seasoning materials were put in the visible place of the dining hall. Thus the re-heating and shaping requirements by customers could be undertaken right in the front stage with helps from the waitresses without bringing disturbance to in-process production in the kitchen by "inserting" the these orders into the already rigid schedule. These measures also encouraged customers' self-services and alleviated production pressure in the kitchen so as to improve the service efficiency while maintaining a quick responsiveness to customers' special needs.
Other functions in back-stage were also reviewed and some of them were re-deployed to the front-offices for a comprehensive and holistic consideration. Seafoodkeeping area, for an instance, was decoupled into two parts. One was the storage area for seafood-keeping; the other was the display part for customer to make orders. The display part was removed from the kitchen to the front-stage, thus minimizing the disturbance caused by customers to the back-stage production.

\subsubsection{Switching from Front-Stage to Back-Stage}

The cashier services were re-designed as a back-stage function rather than front-stage activities as it previously had been. Thus customers needed not go to the cashier counter to pay the bill themselves after dining. Rather they could just inform the waitresses and the latter would help them to conduct the payment activities. With the help of computer-based order system, the cashiers could readily process the bills. When the waitresses come to inform a payment, they could finish processing the bill within seconds since the bills could be pre-processed in the computer before the final payment, and very importantly, they could do the job without contacting the customers who might bring disturbance, which also eliminated the queue before the cashier counter.

The services for drinks preparation and delivery were also switched from a front office function to a back-stage one. Equipped with the computer terminal receiving drinks orders from the PDA held by the waitresses, the bartenders could efficiently arrange the drink preparation just like a store-keeper. To facilitate service delivery the dining hall was divided into several dining areas. The bartenders just put into a cart all the drinks needed in all the order sheets within a specific dinning area. Then the bar assistants would push the carts to corresponding dinning areas and deliver the drinks to the waitresses along the route just as the postmen deliver their mails. The back-stage-style services of drinks preparation and delivery could shorten the lead time greatly and provide more support for the front-line staff since the waitresses needed not fetch the drinks themselves and would not be "absent" from the customer, thus service quality could be improved.

However one reform was not very successful. The restaurant had a dish display area where samples of some master piece of dishes (or dishes in promotion) were displayed for order. The managements of the restaurant held that it had taken up too much space in the front-stage. After the installation of the computer system they transformed it into dinning place and provided customers as a substitution with the picture-based menu and a big-screen projector introducing new dishes. However this seemed not very effective and more customers preferred ordering by seeing the "real" sample dishes rather than the paper or electronic image. 


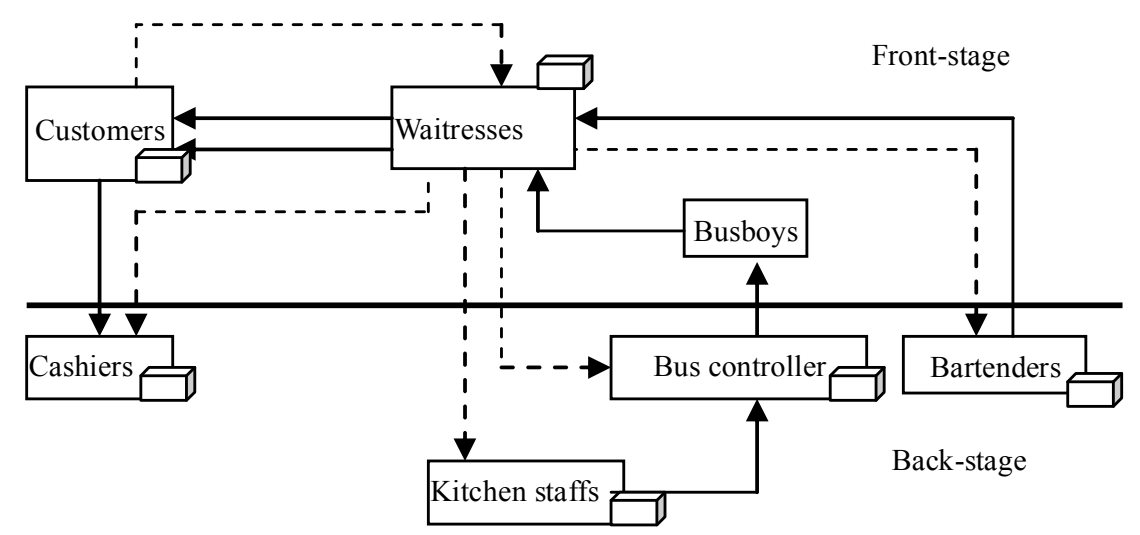

Figure 3. The improved decoupling system

Table 3. Judgment matrix for being in front stage and the calculation of its weight

\begin{tabular}{|c|c|c|c|c|c|c|c|}
\hline & $\mathrm{F}_{1}$ & $\mathrm{~F}_{2}$ & $\mathrm{~F}_{3}$ & $\gamma_{\mathrm{i}}$ & $\gamma_{i}^{0}$ & $\lambda_{\mathrm{i}}$ & \multirow{5}{*}{$\begin{array}{l}\lambda_{\max } \approx 3 . \quad 054 \\
\text { C.I. }=0.027<0.1 \\
\text { R.I. }=0.52 \\
\text { C.R. }=0.052<0.1\end{array}$} \\
\hline $\mathrm{F}_{1}$ & 1 & 4 & 4 & 2.52 & 0.661 & 3.054 & \\
\hline $\mathrm{F}_{2}$ & $1 / 4$ & 1 & 2 & 0.794 & 0.208 & 3.053 & \\
\hline $\mathrm{F}_{3}$ & $1 / 4$ & $1 / 2$ & 1 & 0.500 & 0.131 & 3.054 & \\
\hline \multicolumn{4}{|c|}{ Judgment matrix } & 3. 814 & & & \\
\hline
\end{tabular}

Table 4. Judgment matrix for being in front stage and the calculation of its weight

\begin{tabular}{|c|c|c|c|c|c|c|c|}
\hline & $\mathrm{B}_{1}$ & $\mathrm{~B}_{2}$ & $\mathrm{~B}_{3}$ & $\gamma_{\mathrm{i}}$ & $\gamma_{i}^{0}$ & $\lambda_{\mathrm{i}}$ & $\lambda_{\max } \approx 3 . \quad 094$ \\
\hline $\mathrm{B}_{1}$ & 1 & 5 & 4 & 2.714 & 0.687 & 3.095 & R.I. $=0.52$ \\
\hline $\mathrm{B}_{2}$ & $1 / 5$ & 1 & 2 & 0.737 & 0.186 & 3.093 & C.R. $=0.009<0.1$ \\
\hline $\mathrm{B}_{3}$ & $1 / 4$ & $1 / 2$ & 1 & 0.5 & 0.127 & 3.094 & \\
\hline \multicolumn{4}{|c|}{ Judgment matrix } & 3.951 & & & \\
\hline
\end{tabular}

The improved decoupling service system is shown in Figure 3 ( $\square$ Referring to the computer terminals). Most of the measures took effective finally and the managements of the restaurant were satisfied with our efforts with the regain of revenue and customer satisfaction.

\subsection{Justification of the Judgment Matrix Proposed}

The decoupling decision for cashier services is taken as an example to illustrate the application of the model proposed previously. The cashier service module belonged to "free modules" without high customer contact, and hence could utilize Formula 1 to make decoupling decision. $\gamma_{B \mathrm{i}}$ and $\gamma_{F \mathrm{i}}$ were the focuses of the calculation. Based on Table 2 summarizing the possible benefits gained from putting this module in front or back stage, we take an analysis of the importance of these benefits and give weight to each.

We began with building the Judgment Matrixes. We got the first matrix by comparing the importance in be- tween the three benefits being put in front stage and then conducted the following calculation and consistency test (the normalizing result indicated that this matrix met the requirements and was consistent). The relevant data and the calculation results are shown in Table 3. Similarly, we obtained Table 4 by building and calculating the Judgment Matrix for putting the module in back stage.

From these two tables we got the values for $\gamma_{F i}$ and $\gamma_{B \mathrm{i}}$, respectively $0.661,0.208,0.131$ and $0.687,0.186$, 0.127 .

With the helps from the managers and experts, we got the values of $F_{i}(7,7,3)$ and $B_{j}(7,3,9)$. Thus we could finally figure out:

$$
\sum_{i=1}^{3} F_{i} \gamma_{F i}=6.476 \text { and } \sum_{j=1}^{3} B_{j} \gamma_{B j}=6.591
$$

By using Formula 1 we got $\mathrm{S}$ less than 1 . Therefore the cashier service module should be put in back stage according to proposed model, which coincided with the actual decoupling decision. 


\section{Findings and Discussions}

\subsection{The Effectiveness of Applying Mc Concepts into Service System Decoupling}

System decoupling is regarded as an effective way to deal with the influences caused by customer contact according to previous literatures. But these researches have been based on a dichotomous assumption that service organizations focus on either low costs or high services. The case put the MC concepts and methods into the decoupling of catering service system and tested the effectiveness of those methods in achieving multiple business objectives simultaneously. These include modularization of service system, introduction of technologies and comprehensive consideration on decoupling decisions. These issues and their effectiveness could be justified by most of the successful re-decoupling measures adopted by the sample restaurant.

\subsection{Modularization as a Basis for System Decoupling in Mc}

Modularization is one of the most effective enablers to facilitate mass customization and the premise for system decoupling in mass customization. The case proved this viewpoint in the rationalization of service functions by splitting or merging them. The rationalization in the restaurant was in essence a process of modularization since it had been conducted by utilizing commonalities within service functions and facilitating service provision. The "drinks-service centre", for example, was set up for efficient service delivery by utilizing the commonality among service functions which required cooperation from the drinks service function. The rationalization finally led to identification of more shared service units and decrease of service units over all, which helped a lot to achieve economy of scale while maintaining service quality, reflecting the features of modularization. Additionally the following-up decoupling measures was then based on the service function rationalization or modularization, which also explained the nature of decoupling for MC proposed previously.

\subsection{Balance-Striking among the Multiple Objectives in Decoupling Decision for Mc}

Literatures tell that tradeoffs involved between contact benefits of the front-office operations and the potential efficiency of the back-office with limited or no customer contact. In decoupling process for $\mathrm{MC}$, balance thinking among different operation objectives should be adopted to deal with the tradeoffs involved in decoupling decision for each service module. Namely the system efficiency, service customization, responsiveness and relevant issues should be taken into consideration simultaneously for allocating each individual service module to front or back office. The switching of re-processing job from the kitchen to front-stage, for example, was based on the consideration that the efficiency brought by putting the function in back-stage could not offset the customers' dissatisfaction due to the slow responsiveness (service speed). The re-design of the cashier services into a back-stage function also justified this viewpoint since the benefits from being a front-stage activity could not match the increased efficiency being in the back-stage. This also showed that the operation tradeoffs involved in the decoupling process could be evaluated by carefully comparing the relative importance of the benefits gained from being in front stage and back stage respectively as demonstrated in the model based on Judgment Matrix.

\subsection{Technologies and System Decoupling in Mc}

The vital role of information technology in mass customization operations could be justified by the re-engineering of the information system in the case. Besides, the case address more issues of technologies related to decoupling. The most important criterion for decoupling decision is whether the service function needs customer contact or not. It seems that the nature of the service decide whether customer contact is required. However this has been changed by the development of technologies especially IT which could remove the customer from the service system without affecting service quality, which gives us more flexibility to utilize the decoupling approach. We could find that most of the measures for system re-decoupling in the case linked closely to the use of technologies. The introducing of microwave oven and related equipments enabled the re-processing function moving from back stage to the front stage. The big-screen projector took customers out of the display area and thus saved much space for front stage use. The computer-based order system played very vital role in transferring the cashier and drink preparation services from front stage to back stage. However the use of technologies is not always effective and they can not substitute the customer contact in all cases. The unsuccessful reform in display area of sample dishes in the case justified the point.

\section{Conclusions}

The paper discusses the system decoupling issues in mass customization operation in the context of restaurant services. It justifies that integration of the concept and methods of MC into system decoupling is effective to deal with the operation dilemma and that modularization plays vital role in the decoupling decision-making process. It also explains that the nature of decoupling decision for MC purpose is the allocation of the service modules to front or back stage rater than the physical or geographical separation of service system. Furthermore a 
Judgment-Matrix-based model is proposed on how to make decoupling decisions for mass customization by balancing the multiple operation objectives. Moreover the technologies, especially the IT, are proved to be very important for system decoupling in delivering mass customized services. However the proposed model and implications in the paper need further test in various service contexts for better theoretical generalities, giving the limitations of the case study methodology used in this research.

\section{REFERENCES}

[1] R. B. Chase, "The Customer Contact approach to services: Theoretical based and practical extensions," Operation Research 29, pp. 698-705, 1981.

[2] W. Nie and D. L. Kellogg, "How professors of operations management view service operations?" Production and Operations Management 8, pp. 339-355, 1999.

[3] M. H. Safizadeh, J. M. Field, and L. P. Ritzman, “An empirical analysis of financial services processes with a front-office or back-office orientation," Journal of Operations Management 21, pp. 557-576, 2003.

[4] R. B. Chase and R. H. Hayes, "Beefing up operations in service firms," Sloan Management Review 33, pp. 15-26, 1991.

[5] K. D. Hoffman and J. E. G. Bateson, "Essentials of service marketing," The Dryden Press, Orlando, 1997.

[6] R. B. Chase, "Where does the customer fit in a service operation?" Harvard Business Review 56, pp. 137-142, 1978.

[7] R. B. Chase and D. A. Tansik, "The customer contact model for organization design," Management Science 29, pp. 1037-1050, 1983.

[8] P. Breathnach, "Globalization, information technology and the emergence of Nich transnational cities: The growth of the call centre sector in Dublin," Geoforum 324, pp. 477-485, 2000.

[9] J. L. Heskett, "Lessons in the service sector," Harvard Business Review 65, pp. 118-126, 1987.
[10] J. L. Heskett, W. E. Sasser, and L. A. Schlesinger, "The service profit chain," The Free Press, New York, 1997.

[11] R. B. Chase and N. J. Aquilano, "A matrix for linking marketing and production variables in service system design," In: Richard, D. (eds), Production and Operations Management, 6th edition Irwin, Homewood, 1992.

[12] R. D. Metters and V. Vargas, "A typology of de-coupling strategies in mixed services," Journal of Operations Management 18, pp. 663-682, 2000.

[13] S. M. Davis, "Future perfect," Addison-Wesley, New York, 1987.

[14] B. J. Pine II, B. Victor, and A. C. Boynton, "Making mass customization work," Harvard Business Review 71, pp. 108-119, 1993.

[15] M. M. Tseng and J. Jiao, "Design for mass customization," CIRP Annals 45, pp. 153-156, 1996.

[16] R. Duray, P. Ward, G. Milligan, and W. Berry, “Approaches to mass customization: configurations and empirical validation," Journal of Operation Management 18, pp. 605-625, 2000.

[17] G. D. Silveira, D. Borenstein, and F. S. Fogliatto, "Mass customization: Literature review and research directions," International Journal of Production Economics 72, pp. $1-13,2001$.

[18] K. Turowski, "A virtual electronic call centre solution for mass customization," Proceedings of the 32nd Annual Hawaii International Conference on Systems Sciences, Vol. 8, pp. 8027-8036, 1999.

[19] L. G. Zomerdijk and J. D. Vries, "Structuring front office and back office work in service delivery systems," International Journal of Operations \& Production Management 27, pp. 108-131, 2007.

[20] E. D. Arnheiter and H. Harren, "A typology to unleash the potential of modularity," Journal of Manufacturing Technology Management 16, pp. 699-711, 2005.

[21] C. A. Voss, "Rethinking paradigms of service: Service in a virtual environment," International Journal of Operations \& Production Management 23, pp. 88-104, 2003. 